\title{
Stimulators and Activators of Soluble Guanylate Cyclase: Review and Potential Therapeutic Indications
}

\author{
Bobby Nossaman, ${ }^{1,2}$ Edward Pankey, ${ }^{2}$ and Philip Kadowitz ${ }^{2}$ \\ ${ }^{1}$ Critical Care Medicine Section, Department of Anesthesiology, Ochsner Medical Center, 1514 Jefferson Highway, New Orleans, \\ LA 70121, USA \\ ${ }^{2}$ Department of Pharmacology, SL83, Tulane University School of Medicine, 1430 Tulane Avenue, New Orleans, LA 70112-2699, USA
}

Correspondence should be addressed to Philip Kadowitz, pkadowi@tulane.edu

Received 31 July 2011; Revised 18 November 2011; Accepted 19 November 2011

Academic Editor: Hector R. Wong

Copyright (C 2012 Bobby Nossaman et al. This is an open access article distributed under the Creative Commons Attribution License, which permits unrestricted use, distribution, and reproduction in any medium, provided the original work is properly cited.

The heme-protein soluble guanylyl cyclase (sGC) is the intracellular receptor for nitric oxide (NO). sGC is a heterodimeric enzyme with $\alpha$ and $\beta$ subunits and contains a heme moiety essential for binding of NO and activation of the enzyme. Stimulation of sGC mediates physiologic responses including smooth muscle relaxation, inhibition of inflammation, and thrombosis. In pathophysiologic states, NO formation and bioavailability can be impaired by oxidative stress and that tolerance to NO donors develops with continuous use. Two classes of compounds have been developed that can directly activate sGC and increase cGMP formation in pathophysiologic conditions when NO formation and bioavailability are impaired or when NO tolerance has developed. In this report, we review current information on the pharmacology of heme-dependent stimulators and heme-independent activators of sGC in animal and in early clinical studies and the potential role these compounds may have in the management of cardiovascular disease.

\section{Introduction}

Guanylyl cyclase (GC) is an enzyme that catalyzes the formation of guanosine $3^{\prime}, 5^{\prime}$-monophosphate (cGMP) from guanosine triphosphate (GTP) and is found in tissues throughout the animal kingdom $[1,2]$. Soluble GC (sGC) is the receptor for nitric oxide $(\mathrm{NO})$ in vascular smooth muscle [3, 4]. In the cardiovascular system, NO is endogenously generated by endothelial NO synthase (eNOS) from L-arginine and activates sGC in adjacent vascular smooth muscle cells to increase cGMP levels and induce relaxation (Figure 1). NO plays a major role in the regulation of vascular tone and blood pressure $[5,6]$. When released from the endothelium in response to physiologic stimuli such as shear stress, NO binds to the normally reduced heme moiety of sGC and increases the formation of cGMP from GTP leading to a decrease in intracellular calcium and vasodilation [7-10]. Moreover, the NO-sGC-cGMP pathway is essential for the control of a number of physiologic processes, including neuronal transmission, host defense, cell growth and proliferation, and vascular and platelet homeostasis [11-18].

\section{History}

Initial investigations into the role of $\mathrm{NO}$ were conducted showing that nitrogen-containing compounds such as sodium azide $\left(\mathrm{NaN}_{3}\right)$, sodium nitrite $\left(\mathrm{NaNO}_{2}\right)$, hydroxylamine $\left(\mathrm{NH}_{2} \mathrm{OH}\right)$, nitroglycerin $\left(\mathrm{C}_{3} \mathrm{H}_{5} \mathrm{~N}_{3} \mathrm{O}_{9}\right)$, and sodium nitroprusside $\left(\mathrm{Na}_{2}\left[\mathrm{Fe}(\mathrm{CN})_{5} \mathrm{NO}\right]\right)$ were able to activate $\mathrm{GC}[3,19-$ 23] (Figure 2). When tissues were homogenized and separated by centrifugation, GC activity was detected in particulate and soluble fractions [19, 23-31]. As NO was shown to rapidly activate GC [3], it was hypothesized that GC activation may be due to the effect of NO or another substance that activated the enzyme [19]. Moreover, these nitrogen-containing compounds were able to activate sGC, causing an increase in cGMP, and vascular relaxation $[13,21,32$, 33].

\section{3. sGC in Health and Cardiopulmonary Disease}

Reduced bioavailability and/or responsiveness to endogenous NO have been implicated in the pathogenesis of many 


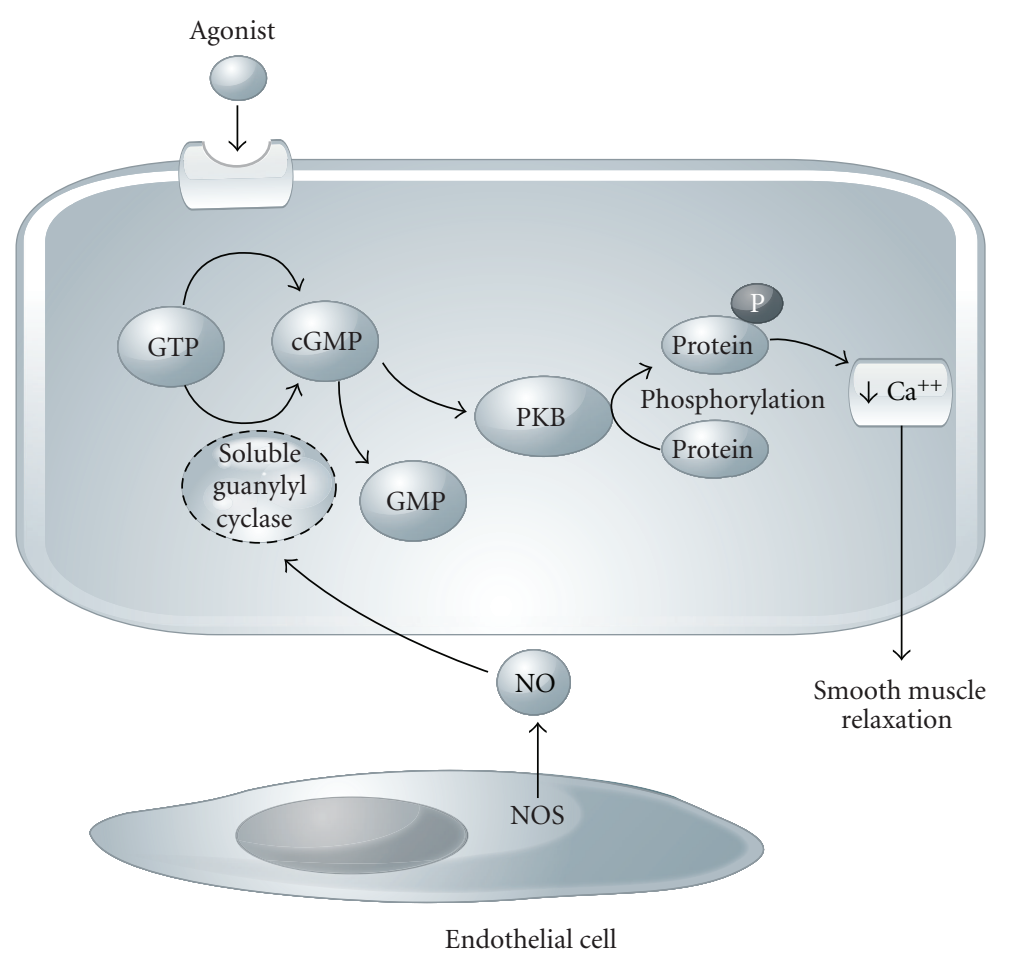

FIGURE 1: Simplified role of NO (nitric oxide) stimulating soluble guanylyl cyclase smooth muscle relaxation. PKB (protein kinase B), NOS (nitric oxide synthase).

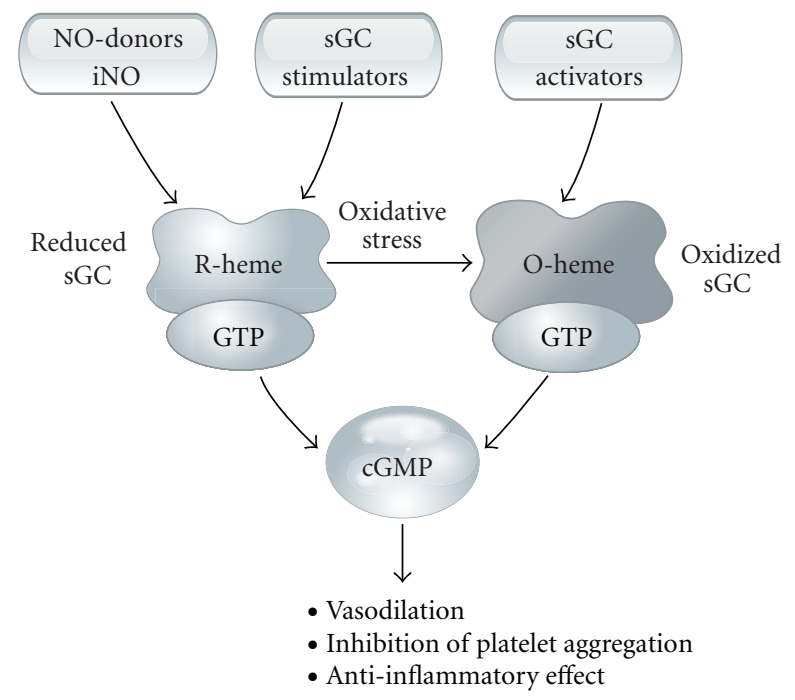

FIGURE 2: Role of NO (nitric oxide), inhaled NO, and sGC (soluble guanylyl cyclase) stimulators in stimulating the reduced heme of sGC and the role of sGC activators in stimulated oxidized sGC to stimulate cGMP leading to vasodilation, inhibition of platelet aggregation and an anti-inflammatory effect in the vascular bed.

disease processes [34-36]. NO was originally described as an endothelial-derived relaxing factor and is a vasodilator in the pulmonary and systemic circulations [37-40]. The significance of $\mathrm{NO}$ in the regulation of vasomotor tone has been demonstrated in experimental animals and in human subjects by the use of NOS inhibitors [41-48]. Given the importance of the NO-sGC-cGMP pathway in cardiopulmonary diseases, there have been enormous efforts to improve NO therapy [36, 49-53].

3.1. Nitrates. Although glyceryl trinitrate (GTN) and amyl nitrite have been used in the treatment of angina pectoris and heart failure for over 140 years $[54,55]$, the most commonly used agents at the present include isosorbide dinitrate, isosorbide-5-mononitrate, and GTN which are effective in reducing ventricular preload by increasing peripheral venous capacitance [56-59]. It is generally believed that the therapeutic effect of these drugs involves the release of $\mathrm{NO}$ from nitrite anion, the activation of sGC, and relaxation of capacitance blood vessels [54, 60-63]. These drugs can also decrease pulmonary and systemic vascular resistances but require higher doses than needed for increasing venous capacitance [64-69]. These agents can reduce ventricular filling pressure, wall stress, and myocardial oxygen consumption [70] and may also improve systolic and diastolic ventricular function by improving coronary flow in patients with ischemic cardiomyopathy. However, there is as yet no convincing evidence that organic nitrates improve mortality in patients with acute myocardial infarction $[71,72]$. The limitations of this class of agents are well known and include adverse hemodynamic effects, including tolerance, lack of selectivity, and limited bioavailability [63].

Studies in the literature provide evidence that vasorelaxant responses to GTN are mediated by the formation of NO or aclosely related S-nitroso molecule [13, 33, 73, 74]. However, the mechanism of this vasorelaxant response to GTN is uncertain. Although studies in the literature indicate 
that NO contributes to the activation of sGC and vascular smooth muscle relaxation $[75,76]$, other studies suggest that vasorelaxant responses to GTN may be independent of NO release and cGMP formation [77].

Studies have shown that the bioactivation of GTN requires the presence of thiols or sulfhydryl-containing compounds and that $\mathrm{NO}$ or NO-like compounds are believed to be the biologically active species $[3,74,78,79]$. Interactions with GTN and sulfhydryl-containing molecules are necessary for vascular smooth muscle relaxation in that repeated administration of GTN produces sulfhydryl depletion and the development of tolerance [79-81]. Subsequent studies have demonstrated the release of NO following the decomposition of an intermediate S-nitrosothiol [74]. Additional studies suggest that an enzymatic mechanism may be responsible for the bioactivation of GTN. However, these enzymatic systems could not catalyze the selective formation of 1,2-glyceryl dinitrate and nitrite from GTN, and moreover, no association between the development of enzymatic tolerance and tolerance to GTN was observed [82-88]. Moreover, the discovery (1) that mitochondrial aldehyde dehydrogenase (mtALDH) generates 1,2-glyceryl dinitrate and nitrite from GTN [89], (2) that this reaction requires a reducing thiol cofactor $[60,90,91]$, and (3) that the activity of this enzyme is reduced in GTN tolerance [53,61] suggests that this pathway is responsible for GTN bioactivation in vascular smooth muscle $[53,77,89]$. However, one difficulty with these studies has been an inability to detect $\mathrm{NO}$ as a byproduct of GTN metabolism [92]. Moreover, the generation of NO was observed when the concentrations of GTN exceeded therapeutic values [93-98]. A potential solution has been proposed that once GTN is bioactivated within the mitochondria, nitrite or an additional action of mtALDH generates the vasodilatory NO bioactivity [53]. One suggested mechanism for this vasodilatory activity is that S-nitrosoglutathione is formed by the reaction of reduced glutathione and nitrite $[99,100]$. This molecule subsequently undergoes biotransformation to S-nitrosocysteine $[89,101]$ that can release NO [102]. However, excessive amounts of GTN or S-nitrosothiols can dysregulate protein S-nitrosylation and contribute to cellular dysfunction and disease [103]. Chronic GTN administration has been shown to result in acetylcholine-induced coronary vasoconstriction rather than relaxation $[104,105]$ and induce endothelial dysfunction [106]. An early event in the development of atherosclerosis is the impairment of endothelial function or endothelial dysfunction that develops before structural changes and intimal hyperplasia or lipid deposition occur [107]. Moreover, reduced oxidation of NO occurs through altered endothelial NOS formation and activity [107], which can be evidenced by abnormal vascular responses to an acetylcholine challenge [108, 109]. Therefore, NO deficiency is linked to cardiopulmonary disease processes and provides justification for the use of effective NO replacement therapy.

\section{Activation of sGC by NO-Like Compounds}

The activation of sGC enhances the conversion of GTP to cGMP that mediates physiologic responses including smooth muscle relaxation and inhibition of platelet aggregation [13-18]. However, little is known about sGC regulation by substances other than NO-donors. The recent discovery of a benzylindazole derivative, YC-1, that was shown to inhibit platelet aggregation and increase by sixfold intracellular concentrations of cGMP, opened up new areas of research in sGC regulation $[110,111]$. Subsequent studies found that activation of sGC by YC-1 was NO-independent and was independent of biotransformation [112, 113]. In contrast, organic nitrates appear to require biotransformation with intermediates (nitrites, nitrosothiols, and organic thionitrates) liberating NO $[91,114]$. These findings with YC-1 as well as other stimulators of sGC suggest that non-NO compounds may also activate or modulate sGC activity [115-118]. Current NO-donor drugs induce tolerance [34-36, 79-81]. However by increasing the responsiveness of sGC to endogenous $\mathrm{NO}, \mathrm{YC}-1$ or $\mathrm{YC}-1$-like compounds may represent a novel class of drugs that cansensitize the sGC enzyme to respond to NO. In disease states with dysfunctional sGC, it may be possible to increase the effect of endogenously produced $\mathrm{NO}$ or improve the effects of NO-donor drugs. NO-independent stimulators for sGC have been developed for use in pathophysiologic conditions when $\mathrm{NO}$ formation and bioavailability are impaired or when NO tolerance has developed [34-36].

\section{1. sGC Stimulators}

4.1.1. Preclinical Studies. Compounds have been developed that can directly stimulate sGC and increase cGMP formation in pathophysiologic conditions when $\mathrm{NO}$ formation and bioavailability are impaired or when NO tolerance has developed [34-36] (Figure 2). The pyrazolopyridine compound, BAY 41-8543, is an NO-independent stimulator of sGC that has been shown to reduce systemic and pulmonary arterial pressure, and relax isolated vessels from a variety of organ systems $[35,119,120]$. BAY 41-2272 is closely related to BAY 41-8543, and this sGC stimulator has been shown to have significant pulmonary vasodilator activity in a variety of species [119, 121-125]. BAY 41-2272 has been shown to reduce right ventricular hypertrophy and pulmonary vascular remodeling in a chronic hypoxia-induced model of pulmonary hypertension [126]. It has been reported that when either BAY 41-2272 or BAY 41-8543 was administered by inhalation to awake lambs, the pyrazolopyridine compounds had selective pulmonary vasodilator activity and BAY 41-8543 could enhance the magnitude and prolong the duration of the vasodilator response to inhaled NO $[122,125]$.

In an intact chest rat model, administration of BAY 41-8543 under control or baseline tone conditions produced small decreases in pulmonary arterial pressure, larger dose-dependent decreases in systemic arterial pressure, and increases in cardiac output [127]. However, under elevated tone conditions induced with the thromboxane receptor agonist, U46619, BAY 41-8543 produced larger dose-dependent decreases in pulmonary arterial pressure when tone in the pulmonary vascular bed was increased [127]. Analyses of the percent decreases in pulmonary and systemic arterial pressures in response to BAY 41-8543 under elevated tone 
conditions induced with U46619-infused animals were not different, suggesting that the sGC stimulator had similar vasodilator activity in the pulmonary and systemic vascular beds in the intact chest rat [127].

The effect of NOS inhibition with L-NAME on vasodilator responses to BAY 41-8543 was investigated in the intact chest rat model, and following administration of the NOS inhibitor, decreases in pulmonary and systemic arterial pressures in response to BAY 41-8543 were reduced when compared to responses in U46619-infused animals. Comparisons of responses to BAY 41-8543 at the same level of pulmonary arterial pressure indicate that decreases in pulmonary arterial pressure in response to the sGC stimulator are reduced by more than 50\% in L-NAME-treated animals [127]. These results are consistent with the concept that responses to the sGC stimulator are NO-independent; however, in the absence of endogenous $\mathrm{NO}$ formation, vasodilator responses to the sGC stimulator were markedly attenuated. It has been reported that stimulators of sGC have a dual role of action in that they directly stimulate the native form of the enzyme and render it more sensitive to endogenously produced $\mathrm{NO}$ or augment the action of exogenously administered NO [125, 128]. The results in the intact chest rat model are consistent with these findings $[125,128]$ that show that vasodilator responses to BAY 41-8543 are attenuated when endogenous NO formation is inhibited.

The role of BAY 41-8543 synergy with exogenous NO was examined in the intact chest model with the NO donor, sodium nitroprusside (SNP). Although separate administration of BAY 41-8543 and SNP produced significant decreases in pulmonary and systemic arterial pressures, coadministration of a small dose of the NO donor along with BAY 41-8543 produced decreases in pulmonary and systemic arterial pressures that were significantly greater than the sum of responses to either agent when administered alone [127]. These results suggest that BAY 41-8543 synergizes with NO in mediating vasodilator responses to the sGC stimulator in the pulmonary and systemic vascular beds in the intact rat.

BAY 41-8543 and BAY 41-2272 were synthesized based upon analysis of the structure of YC-1 [36, 110, 129]. These pyrazolopyridine stimulators activate $\mathrm{SGC}$ in a manner independent of $\mathrm{NO}[35,36,121]$. These compounds activate purified sGC and strongly synergize with NO, reflecting stabilization of the nitrosyl-heme complex of the enzyme [130]. Both BAY 41-8543 and BAY 41-2272 relax vascular smooth muscle and have vasodilator activity in the pulmonary and systemic vascular beds [34, 119, 121, 122, 128, 131].

Although BAY 41-8543 had beneficial effects in experimental models of pulmonary hypertension, this agent does not have favorable pharmacokinetic properties and cannot be used in clinical trials [132]. In contrast, BAY 63-2521 (Riociguat; Bayer Healthcare AG, Wuppertal, Germany), a heme-dependent sGC stimulator closely related to BAY 418543 , has a better pharmacokinetic profile and has been used in clinical studies [132]. In respect to interesting similarities and differences between the actions of BAY 41-8543 and other NO-independent stimulators of sGC, it has been reported that BAY 41-2272, which is chemically similar to BAY 41-8543, produced greater decreases in pulmonary than systemic arterial pressure and that pulmonary vasodilator responses were not attenuated by L-NAME [125]. In the present study, BAY 41-8543 produced similar decreases in pulmonary and systemic arterial pressures in U46619-infused animals and decreases in both pulmonary and systemic arterial pressures attenuated by L-NAME treatment. In an ovine fetal model of pulmonary hypertension, chronic infusion of BAY 41-2272 produced potent sustained decreases in pulmonary arterial pressure that were not attenuated by a NOS inhibitor, L-NA, and when infused at higher rates, systemic arterial pressure was decreased [124]. The main differences in response to stimulators of sGC in the awake sheep, the ovine fetal circulation, and intact chest rat are the relative differences in vasodilator activity in the pulmonary and systemic vascular beds and the role of endogenously produced NO in modulating these responses $[124,125]$. The reason for the differences in results in the different experimental models may involve differences in species, experimental design and preparation, the BAY compound studied, or more importantly, the mechanisms involved in the stimulation of sGC. In the present study, BAY 41-8543 had similar vasodilator activity in the preconstricted pulmonary vascular bed and the systemic vascular bed and vasodilator responses in both beds were attenuated when NOS was inhibited with L-NAME. These data suggest that the role of endogenous $\mathrm{NO}$ in the activation of sGC is similar in both circulations in the intact chest rat model and may differ from SGC activation mechanisms in the pulmonary and systemic vascular beds in the awake sheep and ovine fetal preparation [124, 125].

Although pulmonary vasodilator response to the sGC stimulator, BAY 41-2272, was not dependent on the formation of endogenous NO in the awake sheep model, the response strongly synergized with inhaled NO [125]. Therefore, the ability of the sGC stimulator to synergize with exogenous NO was, in some respects, similar in the awake sheep and intact rat models, although the synergism was much greater in the awake sheep when NO was administered by inhalation [125]. The present results are consistent with the concept that sGC stimulators can be given along with inhaled $\mathrm{NO}$ or an infused NO-donor to produce maximum pulmonary vasodilation $[125,128]$.

4.1.2. Clinical Investigations. The first sGC simulator to undergo clinical study was BAY 41-8543 [34]. However, although systemic blood pressure decreased as expected following oral administration in healthy volunteers, other pharmacokinetic issues occurred that lead to the development of additional sGC compounds [34]. Subsequently BAY 632521 was developed, and when administered in 58 healthy male volunteers as a single oral dose $(0.25-5 \mathrm{mg})$, no serious adverse events were observed [133]. Although both mean arterial and diastolic pressures were decreased, systolic pressure was not significantly affected. A dose-related increase in heart rate up to $\sim 11 \mathrm{bpm}$ was observed with the 5-mg dose; however, this dose was not well tolerated, due to an increased number of adverse events, including headache, nasal congestion, flushing, feeling hot, orthostatic hypotension, and palpitations. Increased levels in the vasoactive hormones, norepinephrine, and plasma renin, but not plasma 
aldosterone or angiotensin II, were observed [133]. Following these encouraging findings, a clinical study was performed to evaluate the short-term safety profile of BAY 632561 (Riociguat) to determine the tolerability and efficacy in patients with moderate to severe pulmonary hypertension $(\mathrm{PH})$ due to pulmonary arterial hypertension, distal chronic thromboembolic $\mathrm{PH}$, or $\mathrm{PH}$ with mild to moderate interstitial lung disease [134]. Safety and tolerability studies were performed in 19 subjects with single doses $\leq 2.5 \mathrm{mg}$. The administration of the sGC stimulator significantly improved pulmonary hemodynamic measurements and cardiac indices in patients with $\mathrm{PH}$ in a dose-dependent manner, to a greater extent than following administration of inhaled NO. Although riociguat had significant systemic blood pressure effects and demonstrated no selectivity for the pulmonary circulation, however, mean systolic blood pressure remained $>110 \mathrm{mmHg}$ [134]. The drug was well tolerated and found to be superior to inhaled NO in the response of the pulmonary circulation [134]. In a 12-week, phase II study, 75 patients with a diagnosis of $\mathrm{PH}$ (chronic thromboembolic pulmonary hypertension or pulmonary arterial hypertension) received oralriociguat in $0.5 \mathrm{mg}$ increments in 2-week intervals from $1 \mathrm{mg}$ to a maximum of $2.5 \mathrm{mg}$ three times a day that was titrated to systemic systolic blood pressure (SBP) [135]. The dose of the sGC stimulator was increased if systemic blood pressure was greater than $100 \mathrm{mmHg}$, was maintained once SBP was stable in a range of $90-100 \mathrm{mmHg}$, and decreased if SBP was less than $90 \mathrm{mmHg}$ or with symptoms such as syncope or dizziness. The primary endpoints studied were safety and tolerability of the sGC stimulator with changes in pharmacodynamics as the secondary endpoints. Riociguat was well tolerated, and that asymptomatic hypotension (SBP less than $90 \mathrm{mmHg}$ ) occurred in 11/75 (15\%) patients, but blood pressure could be normalized with dose alteration in $2 \mathrm{pa}-$ tients and without dose alteration in 9 patients [135]. Pulmonary vascular resistance was significantly reduced. A significant improvement in the median 6-minute walking distance was observed in patients with diagnosis of chronic thromboembolic pulmonary hypertension (greater than 55 meters; $P<0.0001$ ) and in patients with pulmonary arterial hypertension (PAH) (greater than 57 meters; $P<0.0001$ ). Moreover, similar improvements were also observed in patients on chronic bosentan therapy [135]. The most frequent observed adverse events were dyspepsia, headache, and hypotension but were considered mild or moderate in $96 \%$ in these patients. Only in $4 \%$ of patients was the medication discontinued. In this 12-week study, the sGC stimulator demonstrated a favorable safety profile with significant improvements in pulmonary hemodynamics, and in exercise capacity, but with a high through mild to moderate incidence of patient symptoms [135].

\section{2. sGC Activators}

4.2.1. Preclinical Studies. The oxidation of the heme iron on sGC decreases the responsiveness of the enzyme to NO and promotes vasoconstriction [136]. Recently, stimulatory compounds with a different mode of sGC activation have been developed and have been shown to target NO receptor proteins when the heme iron on sGC is in an oxidized $\left(\mathrm{Fe}^{3+}\right.$ instead of $\left.\mathrm{Fe}^{2+}\right)$ state, or when the heme group is lost [36, $131,137,138$ ] (Figure 2). These compounds activate the oxidized or heme-deficient sGC enzyme that is not responsive to $\mathrm{NO}$ [51]. Oxidation of $\mathrm{sGC}$ results in loss of activation of the enzyme [139-142]. Moreover, purified sGC also results in marked to complete loss of enzyme responsiveness to NOdonors $[143,144]$. However, responsiveness was restored by the addition of hematin, hemoglobin, or a heat-inactivated catalase in the presence of a reducing agent $[143,144]$. Organic nitrates have been used in the treatment of angina, but the development of tolerance limits their therapeutic value [53, $60,145-147]$. The development of compounds that overcome this limitation that are able to stimulate sGC independent of redox state as shown in tissue preparations and in vivo studies indicates that these NO-independent receptors exist and may become more abundant under pathological conditions associated with oxidative stress [148-150].

Activation of the NO-sGC-cGMP pathway can induce potent pulmonary and systemic vasodilatation [40, 151155]. Two classes of novel drugs have been developed that can modulate sGC-cGMP signal transduction in an NOindependent manner. Although stimulators of sGC can enhance the sensitivity of reduced sGC to NO [127], activators of sGC can increase sGC enzyme activity even when the enzyme is oxidized and less, or not responsive, to $\mathrm{NO}[34,51$, $52,156]$. In the intact chest rat, intravenous administration of the sGC activator, BAY 60-2770, produced dose-related decreases in systemic arterial pressure, increases in cardiac output, and decreases in systemic vascular resistance, and the cardiovascular responses were slow in onset and long in duration [157]. These observations are comparable to the findings in the anesthetized dog following administration of another sGC activator, BAY 41-2272 [123]. These findings suggest that sGC activators can increase sGC enzyme activity in vascular beds from different species $[123,157]$.

Following a preclinical study in rats demonstrating that Cinaciquat was able to reduce oxidative stress, improve cardiac performance, and improve impaired cardiac relaxation in experimentally induced myocardial infarction in rats [158], the role of the sGC activator in ischemia-reperfusion injury was investigated in a canine model of cardioplegic arrest and extracorporeal circulation [159]. Preconditioning with the sGC activator improved left- and right-ventricular contractility and led to a higher coronary blood flow. Moreover, endothelium-dependent vasodilatation to acetylcholine was improved. These findings suggest that preconditioning with Cinaciguat could improve myocardial and endothelial function following cardiopulmonary bypass and could be a novel therapeutic option in the protection against ischemiareperfusion injury in cardiac surgery [159].

Vasodilator responses to this novel class of drugs have been studied in experimental models under conditions of acute pulmonary hypertension $(\mathrm{PH})$ induced with the stable endoperoxide analogue, U46619 [122, 128]. In the intact chest rat under elevated pulmonary arterial tone conditions induced with U46619, administration of BAY 60-2770 produced significant decreases in both pulmonary and systemic arterial pressure [157]. Intravenous infusion of the sGC 
stimulator, BAY 41-2272, or inhalation of the sGC activator, BAY 58-2667, was able to reduce mean pulmonary arterial pressure and pulmonary vascular resistance in awake lambs $[122,128]$. However, in contrast to the modest systemic pressure changes observed following administration of the sGC activator, BAY 58-2667, in the awake lamb [128], significant decreases in systemic arterial pressure were observed following administration of the sGC activator, BAY 60-2770, in the intact chest rat model [157]. The differences in results could be due to the type of sGC activator administered, experimental conditions, or species studied.

4.2.2. Clinical Studies. The development of heart failure due to a number of etiologies is a common final stage in cardiovascular disease that is associated with high morbidity and mortality [160]. Stimulation of sGC with conventional nitrosovasodilators has been used for more than a century, but the development of tolerance, due to the prosthetic heme group of sGC existing in an oxidized or heme-free state, limits their clinical effectiveness [161, 162]. BAY 58-2667 (Cinaciguat; Bayer Healthcare AG, Wuppertal, Germany) has been shown to preferentially activate sGC when the prostetic heme group is in an oxidized or heme-free state [131]. As a result, Cinaciguat induces cGMP generation and vasodilation preferentially in diseased vessels $[35,121,149]$ and has the potential to induce vasodilation and increase cardiac output in patients with HF. In the first clinical study with this sGC activator, the safety, tolerability, pharmacokinetics, and pharmacodynamics were analyzed in 76 healthy volunteers [163]. An intravenous infusion of Cinaciguat in a range of 50 to $250 \mathrm{mcg} / \mathrm{h}$ was administered for up to 4 hours. During the infusion period, the sGC activator decreased diastolic blood pressure and increased heart rate without significantly reducing systolic blood pressure. No serious adverse events were observed. However, at the higher infusion rates (150$250 \mathrm{mcg} / \mathrm{h}$ ), a decrease in mean arterial pressure and an increase in plasma cGMP levels were observed. The findings that Cinaciguat had potent cardiovascular effects by reducing both preload and after load suggested that further investigation should occur in patients with HF [163]. In a multicenter phase II study, patients with a diagnosis of acute decompensated heart failure received 6-hour intravenous infusions of Cinaciguat which produced significant reductions in pulmonary capillary wedge pressure, mean right atrial pressure, mean pulmonary artery pressure, pulmonary vascular resistance, and systemic vascular resistance, and cardiac output by $1.7 \mathrm{~L} / \mathrm{min}$ while only increasing heart rates by $4 \mathrm{bpm}$ [164]. Cinaciguat was well tolerated in these patients, with approximately one-fourth of the patients reporting adverse events of mild to moderate intensity, with hypotension as the most common adverse event [164]. These results clearly demonstrate the clinical efficacy of the sCG activator.

\section{Clinical Correlations}

As sGC stimulators have been shown to stimulate sGC independently of NO donors, this class of agonists could have an important role in the acute hospital setting when a sudden increase in pulmonary vascular tone can occur during sympathetic overstimulation following major surgery that would be refractory to conventional NO-donor therapy, such as in patients who develop ARDS and are refractory to inhaled NO (iNO). The application of sGC stimulators would then make iNO therapy more effective in the treatment of acute pulmonary hypertension and possibly decease the incidence of associated right ventricular heart failure.

In contrast to the benefits from sGC stimulators, the application of sGC activators may have an important role in the therapeutic management of chronic-diseased blood vessels with extended periods of efficacy such as seen in systemic hypertension, atherosclerosis, diabetes mellitus, angina, and heart failure. Moreover, the use of this class of drugs may reduce the development of oxidative stress from $\mathrm{NO}$-donor therapy and may reduce the common side effects from NOdonor therapy such as headache that would improve patient compliance.

\section{Conclusion}

Research has shown that heme-dependent drugs are effective in the treatment of cardiopulmonary disorders, but that their effects are diminished under pathological conditions associated with increased oxidative stress and the development of tolerance. In the past decade, the development of heme-independent compounds has been shown to higher affinities for the oxidized form of sGC, and they are being developed for the treatment of acute decompensated heart failure and pulmonary hypertension. These two classes of drugs, sGC stimulators and sGC activators, have been studied in animal studies. These compounds are now undergoing preliminary clinical trials and may be available for clinical use within the near future.

\section{References}

[1] J. G. Hardman and E. W. Sutherland, "Guanyl cyclase, an enzyme catalyzing the formation of guanosine 3'5'-monophosphate from guanosine trihosphate," Journal of Biological Chemistry, vol. 244, no. 23, pp. 6363-6370, 1969.

[2] J. G. Hardman, J. W. Davis, and E. W. Sutherland, "Effects of some hormonal and other factors on the excretion of guanosine 3',5'-monophosphate and adenosine 3',5'-monophosphate in rat urine," Journal of Biological Chemistry, vol. 244, no. 23, pp. 6354-6362, 1969.

[3] W. P. Arnold, C. K. Mittal, S. Katsuki, and F. Murad, "Nitric oxide activates guanylate cyclase and increases guanosine 3':5'-cyclic monophosphate levels in various tissue preparations," Proceedings of the National Academy of Sciences of the United States of America, vol. 74, no. 8, pp. 3203-3207, 1977.

[4] D. B. McNamara, P. J. Kadowitz, A. L. Hyman, and L. J. Ignarro, "Adenosine 3', 5'-monophosphate formation by preparations of rat liver soluble guanylate cyclase activated with nitric oxide, nitrosyl ferroheme, S-nitrosothiols, and other nitroso compounds," Canadian Journal of Physiology and Pharmacology, vol. 58, no. 12, pp. 1446-1456, 1980.

[5] S. Moncada, R. M. J. Palmer, and E. A. Higgs, "The discovery of nitric oxide as the endogenous nitrovasodilator," Hypertension, vol. 12, no. 4, pp. 365-372, 1988. 
[6] S. Moncada and E. A. Higgs, "Nitric oxide and the vascular endothelium," Handbook of Experimental Pharmacology, no. 176, pp. 213-254, 2006.

[7] J. R. Stone and M. A. Marletta, "Spectral and kinetic studies on the activation of soluble guanylate cyclase by nitric oxide," Biochemistry, vol. 35, no. 4, pp. 1093-1099, 1996.

[8] B. Wedel, P. Humbert, C. Harteneck et al., "Mutation of His105 in the $\beta 1$ subunit yields a nitric oxide-insensitive form of soluble guanylyl cyclase," Proceedings of the National Academy of Sciences of the United States of America, vol. 91, no. 7, pp. 2592-2596, 1994.

[9] L. J. Ignarro, J. N. Degnan, W. H. Baricos, P. J. Kadowitz, and M. S. Wolin, "Activation of purified guanylate cyclase by nitric oxide requires heme comparison of heme-deficient, heme-reconstituted and heme-containing forms of soluble enzyme from bovine lung," Biochimica et Biophysica Acta, vol. 718, no. 1, pp. 49-59, 1982.

[10] P. A. Craven and F. R. DeRubertis, "Requirement for heme in the activation of purified guanylate cyclase by nitric oxide," Biochimica et Biophysica Acta, vol. 745, no. 3, pp. 310-321, 1983.

[11] S. R. Vincent, "Nitric oxide neurons and neurotransmission," Progress in Neurobiology, vol. 90, no. 2, pp. 246-255, 2010.

[12] K. Domek-Łopacińska and J. B. Strosznajder, "Cyclic GMP metabolism and its role in brain physiology," Journal of Physiology and Pharmacology, vol. 56, supplement 2, pp. 15-34, 2005.

[13] C. A. Gruetter, B. K. Barry, D. B. McNamara, D. Y. Gruetter, L. Ignarro, and P. J. Kadowitz, "Relaxation of bovine coronary artery and activation of coronary arterial guanylate cyclase by nitric oxide, nitroprusside and a carcinogenic nitrosoamine," Journal of Cyclic Nucleotide Research, vol. 5, no. 3, pp. 211$224,1979$.

[14] L. J. Ignarro, R. G. Harbison, K. S. Wood, and P. J. Kadowitz, "Dissimilarities between methylene blue and cyanide on relaxation and cyclic GMP formation in endothelium-intact intrapulmonary artery caused by nitrogen oxide-containing vasodilators and acetylcholine," Journal of Pharmacology and Experimental Therapeutics, vol. 236, no. 1, pp. 30-36, 1986.

[15] R. Busse, A. Luckhoff, and E. Bassenge, "Endotheliumderived relaxant factor inhibits platelet activation," NaunynSchmiedeberg's Archives of Pharmacology, vol. 336, no. 5, pp. 566-571, 1987.

[16] A. J. Barber, "Cyclic nucleotides and platelet aggregation: effect of aggregating agents on the activity of cyclic nucleotide metabolizing enzymes," Biochimica et Biophysica Acta, vol. 444, no. 2, pp. 579-595, 1976.

[17] B. T. Mellion, L. J. Ignarro, C. B. Myers et al., "Inhibition of human platelet aggregation by S-nitrosothiols: heme-dependent activation of soluble guanylate cyclase and stimulation of cyclic GMP accumulation," Molecular Pharmacology, vol. 23, no. 3, pp. 653-664, 1983.

[18] B. T. Mellion, L. J. Ignarro, E. H. Ohlstein, E. G. Pontecorvo, A. L. Hyman, and P. J. Kadowitz, "Evidence for the inhibitory role of guanosine 3',5'-monophosphate in ADP-induced human platelet aggregation in the presence of nitric oxide and related vasodilators," Blood, vol. 57, no. 5, pp. 946-955, 1981.

[19] S. Katsuki, W. Arnold, C. Mittal, and F. Murad, "Stimulation of guanylate cyclase by sodium nitroprusside, nitroglycerin and nitric oxide in various tissue preparations and comparison to the effects of sodium azide and hydroxylamine," Journal of Cyclic Nucleotide Research, vol. 3, no. 1, pp. 23-35, 1977.
[20] H. Kimura, C. K. Mittal, and F. Murad, "Activation of guanylate cyclase from rat liver and other tissues by sodium azide," Journal of Biological Chemistry, vol. 250, no. 20, pp. 8016-8022, 1975.

[21] C. K. Mittal, H. Kimura, and F. Murad, "Requirement for a macromolecular factor for sodium azide activation of guanylate cyclase," Journal of Cyclic Nucleotide Research, vol. 1, no. 5, pp. 261-269, 1975.

[22] S. Katsuki, W. P. Arnold, and F. Murad, "Effects of sodium nitroprusside, nitroglycerin, and sodium azide on levels of cyclic nucleotides and mechanical activity of various tissues," Journal of Cyclic Nucleotide Research, vol. 3, no. 4, pp. 239249, 1977.

[23] W. E. Criss, F. Murad, and H. Kimura, "Properties of guanylate cyclase from rat kidney cortex and transplantable kidney tumors," Journal of Cyclic Nucleotide Research, vol. 2, no. 1, pp. 11-19, 1976.

[24] T. Deguchi, "Endogenous activating factor for guanylate cyclase in synaptosomal-soluble fraction of rat brain," Journal of Biological Chemistry, vol. 252, no. 21, pp. 7617-7619, 1977.

[25] D. L. Garbers, J. L. Suddath, and J. G. Hardman, "Enzymatic formation of inosine 3',5' monophosphate and of 2' deoxyguanosine 3',5' monophosphate: inosinate and deoxyguanylate cyclase activity," Biochimica et Biophysica Acta, vol. 377, no. 1, pp. 174-185, 1975.

[26] H. Kimura and F. Murad, "Localization of particulate guanylate cyclase in plasma membranes and microsomes of rat liver," Journal of Biological Chemistry, vol. 250, no. 12, pp. 4810-4817, 1975.

[27] E. Busse, "Proof of guanylate cyclase activity in the coronary artery of cattle," Acta Biologica et Medica Germanica, vol. 35, no. 12, pp. 1595-1601, 1976.

[28] T. Deguchi, E. Amano, and M. Nakane, "Subcellular distribution and activation by non ionic detergents of guanylate cyclase in cerebral cortex of rat," Journal of Neurochemistry, vol. 27, no. 5, pp. 1027-1034, 1976.

[29] T. Deguchi, "Activation of guanylate cyclase in cerebral cortex of rat by hydroxylamine," Journal of Biological Chemistry, vol. 252, no. 2, pp. 596-601, 1977.

[30] D. D. Mahaffee and D. A. Ontjes, "Properties of adenylate cyclase solubilized from rat adrenal membranes: effects of ACTH and other stimulators on solubilization," Journal of Cyclic Nucleotide Research, vol. 3, no. 5, pp. 325-334, 1977.

[31] K. B. Nilsson and G. G. Andersson, "Effects of carbachol and calcium on the cyclic guanosine 3',5' monophosphate (cyclic GMP) metabolism in intestinal smooth muscle," Acta Physiologica Scandinavica, vol. 99, no. 2, pp. 246-253, 1977.

[32] S. Katsuki and F. Murad, "Regulation of adenosine cyclic 3',5' monophosphate and guanosine cyclic 3',5' monophosphate levels and contractility in bovine tracheal smooth muscle," Molecular Pharmacology, vol. 13, no. 2, pp. 330-341, 1977.

[33] C. A. Gruetter, P. J. Kadowitz, and L. J. Ignarro, "Methylene blue inhibits coronary arterial relaxation and guanylate cyclase activation by nitroglycerin, sodium nitrite, and amyl nitrite," Canadian Journal of Physiology and Pharmacology, vol. 59, no. 2, pp. 150-156, 1981.

[34] J. P. Stasch and A. J. Hobbs, "NO-independent, haem-dependent soluble guanylate cyclase stimulators," Handbook of Experimental Pharmacology, vol. 191, pp. 277-308, 2009.

[35] A. Straub, J. P. Stasch, C. Alonso-Alija et al., "NO-independent stimulators of soluble guanylate cyclase," Bioorganic and Medicinal Chemistry Letters, vol. 11, no. 6, pp. 781-784, 2001. 
[36] O. V. Evgenov, P. Pacher, P. M. Schmidt, G. Haskó, H. H. H. W. Schmidt, and J. P. Stasch, "NO-independent stimulators and activators of soluble guanylate cyclase: discovery and therapeutic potential," Nature Reviews Drug Discovery, vol. 5, no. 9, pp. 755-768, 2006.

[37] R. F. Furchgott and J. V. Zawadzki, "The obligatory role of endothelial cells in the relaxation of arterial smooth muscle by acetylcholine," Nature, vol. 288, no. 5789, pp. 373-376, 1980.

[38] L. J. Ignarro, "Endothelium-derived nitric oxide: pharmacology and relationship to the actions of organic nitrate esters," Pharmaceutical Research, vol. 6, no. 8, pp. 651-659, 1989.

[39] L. J. Ignarro, R. E. Byrns, G. M. Buga, and K. S. Wood, "Endothelium-derived relaxing factor from pulmonary artery and vein possesses pharmacologic and chemical properties identical to those of nitric oxide radical," Circulation Research, vol. 61, no. 6, pp. 866-879, 1987.

[40] L. J. Ignarro, R. G. Harbison, K. S. Wood, and P. J. Kadowitz, "Activation of purified soluble guanylate cyclase by endothelium-derived relaxing factor from intrapulmonary artery and vein: stimulation by acetylcholine, bradykinin and arachidonic acid," Journal of Pharmacology and Experimental Therapeutics, vol. 237, no. 3, pp. 893-900, 1986.

[41] T. J. McMahon, J. S. Hood, and P. J. Kadowitz, "Pulmonary vasodilator response to vagal stimulation is blocked by $\mathrm{N}(\omega)$ nitro-L-arginine methyl ester in the cat," Circulation Research, vol. 70, no. 2, pp. 364-369, 1992.

[42] B. Hauser, H. Bracht, M. Matejovic, P. Radermacher, and B. Venkatesh, "Nitric oxide synthase inhibition in sepsis? Lessons learned from large-animal studies," Anesthesia and Analgesia, vol. 101, no. 2, pp. 488-498, 2005.

[43] M. L. Blitzer, E. Loh, M. A. Roddy, J. S. Stamler, and M. A. Creager, "Endothelium-derived nitric oxide regulates systemic and pulmonary vascular resistance during acute hypoxia in humans," Journal of the American College of Cardiology, vol. 28, no. 3, pp. 591-596, 1996.

[44] J. A. Bellan, R. K. Minkes, D. B. McNamara, and P. J. Kadowitz, "N( $\omega)$-nitro-L-arginine selectively inhibits vasodilator responses to acetylcholine and bradykinin in cats," American Journal of Physiology, vol. 260, no. 3, pp. H1025-H1029, 1991.

[45] T. J. McMahon, J. S. Hood, J. A. Bellan, and P. J. Kadowitz, " $\mathrm{N}(\omega)$-nitro-L-arginine methyl ester selectively inhibits pulmonary vasodilator responses to acetylcholine and bradykinin," Journal of Applied Physiology, vol. 71, no. 5, pp. 20262031, 1991.

[46] J. A. Panza, P. R. Casino, C. M. Kilcoyne, and A. A. Quyyumi, "Role of endothelium-derived nitric oxide in the abnormal endothelium- dependent vascular relaxation of patients with essential hypertension," Circulation, vol. 87, no. 5, pp. 14681474, 1993.

[47] T. Lauer, M. Preik, T. Rassaf et al., "Plasma nitrite rather than nitrate reflects regional endothelial nitric oxide synthase activity but lacks intrinsic vasodilator action," Proceedings of the National Academy of Sciences of the United States of America, vol. 98, no. 22, pp. 12814-12819, 2001.

[48] A. A. Quyyumi, N. Dakak, N. P. Andrews, D. M. Gilligan, J. A. Panza, and R. O. Cannon III, "Contribution of nitric oxide to metabolic coronary vasodilation in the human heart," Circulation, vol. 92, no. 3, pp. 320-326, 1995.

[49] T. F. Luscher, "Endogenous and exogenous nitrates and their role in myocardial ischaemia," British Journal of Clinical Pharmacology, vol. 34, supplement 1, pp. 29S-35S, 1992.
[50] G. R. J. Thatcher, A. C. Nicolescu, B. M. Bennett, and V. Toader, "Nitrates and NO release: contemporary aspects in biological and medicinal chemistry," Free Radical Biology and Medicine, vol. 37, no. 8, pp. 1122-1143, 2004.

[51] H. H. H. W. Schmidt, P. M. Schmidt, and J. P. Stasch, "NOand haem-independent soluble guanylate cyclase activators," Handbook of Experimental Pharmacology, vol. 191, pp. 309339, 2009.

[52] F. B. M. Priviero and R. C. Webb, "Heme-dependent and independent soluble guanylate cyclase activators and vasodilation," Journal of Cardiovascular Pharmacology, vol. 56, no. 3, pp. 229-233, 2010.

[53] B. Mayer and M. Beretta, "The enigma of nitroglycerin bioactivation and nitrate tolerance: news, views and troubles," British Journal of Pharmacology, vol. 155, no. 2, pp. 170-184, 2008.

[54] W. Murrell, "Nitro-Glycerine in angina pectoris," The Lancet, vol. 1 , pp. $80-81,1879$.

[55] T. L. Brunton, "On the use of nitrite of amyl in angina pectoris," The Lancet, vol. 90, no. 2291, pp. 97-98, 1867.

[56] M. G. Bogaert, "Organic nitrates in angina pectoris," Archives Internationales de Pharmacodynamie et de Therapie, vol. 196, supplement 196, p. 125, 1972.

[57] D. J. Battock, P. W. Levitt, and P. P. Steele, "Effects of isosorbide dinitrate and nitroglycerin on central circulatory dynamics in coronary artery disease," American Heart Journal, vol. 92, no. 4, pp. 455-458, 1976.

[58] S. Silber, "Nitrates: why and how should they be used today? Current status of the clinical usefulness of nitroglycerin, isosorbide dinitrate and isosorbide-5-mononitrate," European Journal of Clinical Pharmacology, vol. 38, supplement 1, pp. S35-S51, 1990.

[59] J. A. Parker, "Organic nitrates: new formulations and their clinical advantages," American Journal of Cardiology, vol. 77, no. 13, pp. 38C-40C, 1996.

[60] J. D. Artz, B. Schmidt, J. L. McCracken, and M. A. Marletta, "Effects of nitroglycerin on soluble guanylate cyclase: implications for nitrate tolerance," Journal of Biological Chemistry, vol. 277, no. 21, pp. 18253-18256, 2002.

[61] M. Beretta, K. Gruber, A. Kollau et al., "Bioactivation of nitroglycerin by purified mitochondrial and cytosolic aldehyde dehydrogenases," Journal of Biological Chemistry, vol. 283, no. 26, pp. 17873-17880, 2008.

[62] D. B. Casey, A. M. Badejo Jr., J. S. Dhaliwal et al., "Pulmonary vasodilator responses to sodium nitrite are mediated by an allopurinol-sensitive mechanism in the rat," American Journal of Physiology, vol. 296, no. 2, pp. H524-H533, 2009.

[63] L. J. Ignarro, C. Napoli, and J. Loscalzo, "Nitric oxide donors and cardiovascular agents modulating the bioactivity of nitric oxide: an overview," Circulation Research, vol. 90, no. 1, pp. 21-28, 2002.

[64] J. B. Johnson, A. Fairley, and C. Carter, "Effects of sublingual nitroglycerin on pulmonary arterial pressure in patients with left ventricular failure," Annals of Internal Medicine, vol. 50, no. 1, pp. 34-42, 1959.

[65] R. E. Fremont, "The actions of organic nitrates on the cardiopulmonary and peripheral circulations," Angiology, vol. 12, pp. 391-400, 1961.

[66] E. Mikulic, J. A. Franciosa, and J. N. Cohn, "Comparative hemodynamic effects of chewable isosorbide dinitrate and nitroglycerin in patients with congestive heart failure," Circulation, vol. 52, no. 3, pp. 477-482, 1975. 
[67] Y. Charuzi, "Use of nitroglycerin ointment in acute pulmonary edema and hypertension," Chest, vol. 82, no. 6, p. 800, 1982.

[68] H. I. Palevsky and A. P. Fishman, "Vasodilator therapy for primary pulmonary hypertension," Annual Review of Medicine, vol. 36, pp. 563-578, 1985.

[69] H. Bundgaard, S. Boesgaard, S. A. Mortensen, H. Arendrup, and J. Aldershvile, "Effect of nitroglycerin in patients with increased pulmonary vascular resistance undergoing cardiac transplantation," Scandinavian Cardiovascular Journal, vol. 31, no. 6, pp. 339-342, 1997.

[70] A. S. Pearlman, R. L. Engler, R. A. Goldstein, K. M. Kent, and S. E. Epstein, "Relative effects of nitroglycerin and nitroprusside during experimental acute myocardial ischemia," European Journal of Cardiology, vol. 11, no. 4, pp. 295-313, 1980.

[71] GISSI-3 Investigators, "GISSI-3: effects of lisinopril and transdermal glyceryl binitrate singly and together on 6-week mortality and ventricular function after acute myocardial infarction. Gruppo Italiano per lo Studio della Sopravvivenza nell'infarto Miocardico," The Lancet, vol. 343, no. 8906, pp. 1115-1122, 1994.

[72] B. I. Jugdutt, "Nitrates in myocardial infarction," Cardiovascular Drugs and Therapy, vol. 8, no. 4, pp. 635-646, 1994.

[73] H. L. Lippton, C. A. Gruetter, L. J. Ignarro, R. L. Meyer, and P. J. Kadowitz, "Vasodilator actions of several N-nitroso compounds," Canadian Journal of Physiology and Pharmacology, vol. 60, no. 1, pp. 68-75, 1982.

[74] L. J. Ignarro, H. Lippton, J. C. Edwards et al., "Mechanism of vascular smooth muscle relaxation by organic nitrates, nitrites, nitroprusside and nitric oxide: evidence for the involvement of S-Nitrosothiols as active intermediates," Journal of Pharmacology and Experimental Therapeutics, vol. 218, no. 3, pp. 739-749, 1981.

[75] L. J. Ignarro and C. A. Gruetter, "Requirement of thiols for activation of coronary arterial guanylate cyclase by glyceryl trinitrate and sodium nitrite: possible involvement of S-nitrosothiols," Biochimica et Biophysica Acta, vol. 631, no. 2, pp. 221-231, 1980.

[76] G. Kojda, M. Patzner, A. Hacker, and E. Noack, "Nitric oxide inhibits vascular bioactivation of glyceryl trinitrate: a novel mechanism to explain preferential venodilation of organic nitrates," Molecular Pharmacology, vol. 53, no. 3, pp. 547$554,1998$.

[77] Z. Chen, J. Zhang, and J. S. Stamler, "Identification of the enzymatic mechanism of nitroglycerin bioactivation," Proceedings of the National Academy of Sciences of the United States of America, vol. 99, no. 12, pp. 8306-8311, 2002.

[78] F. Murad, C. K. Mittal, W. P. Arnold, S. Katsuki, and H. Kimura, "Guanylate cyclase: activation by azide, nitro compounds, nitric oxide, and hydroxyl radical and inhibition by hemoglobin and myoglobin," Advances in Cyclic Nucleotide Research, vol. 9, pp. 145-158, 1978.

[79] P. Needleman, B. Jakschik, and E. M. Johnson Jr., "Sulfhydryl requirement for relaxation of vascular smooth muscle," Journal of Pharmacology and Experimental Therapeutics, vol. 187, no. 2, pp. 324-331, 1973.

[80] P. Needleman, “Organic nitrate metabolism," Annual Review of Pharmacology and Toxicology, vol. 16, pp. 81-93, 1976.

[81] P. Needleman and E. M. Johnson Jr., "Mechanism of tolerance development to organic nitrates," Journal of Pharmacology and Experimental Therapeutics, vol. 184, no. 3, pp. 709715, 1973.
[82] S. Tsuchida, T. Maki, and K. Sato, "Purification and characterization of glutathione transferases with an activity toward nitroglycerin from human aorta and heart: multiplicity of the human class Mu forms," Journal of Biological Chemistry, vol. 265, no. 13, pp. 7150-7157, 1990.

[83] R. A. Yeates, M. Schmid, and M. Leitold, "Antagonism of glycerol trinitrate activity by an inhibitor of glutathione S-transferase," Biochemical Pharmacology, vol. 38, no. 11, pp. 1749-1753, 1989.

[84] T. M. Millar, C. R. Stevens, N. Benjamin, R. Eisenthal, R. Harrison, and D. R. Blake, "Xanthine oxidoreductase catalyses the reduction of nitrates and nitrite to nitric oxide under hypoxic conditions," FEBS Letters, vol. 427, no. 2, pp. 225228, 1998.

[85] B. J. McDonald and B. M. Bennett, "Cytochrome P-450 mediated biotransformation of organic nitrates," Canadian Journal of Physiology and Pharmacology, vol. 68, no. 12, pp. 15521557, 1990.

[86] B. J. McDonald and B. M. Bennett, "Biotransformation of glyceryl trinitrate by rat aortic cytochrome P450," Biochemical Pharmacology, vol. 45, no. 1, pp. 268-270, 1993.

[87] P. Seth and H. L. Fung, "Biochemical characterization of a membrane-bound enzyme responsible for generating nitric oxide from nitroglycerin in vascular smooth muscle cells," Biochemical Pharmacology, vol. 46, no. 8, pp. 1481-1486, 1993.

[88] J. J. McGuire, D. J. Anderson, B. J. McDonald, R. Narayanasami, and B. M. Bennett, "Inhibition of NADPHcytochrome P450 reductase and glyceryl trinitrate biotransformation by diphenyleneiodonium sulfate," Biochemical Pharmacology, vol. 56, no. 7, pp. 881-893, 1998.

[89] Z. Chen, M. W. Foster, J. Zhang et al., "An essential role for mitochondrial aldehyde dehydrogenase in nitroglycerin bioactivation," Proceedings of the National Academy of Sciences of the United States of America, vol. 102, no. 34, pp. 12159-12164, 2005.

[90] M. Packer, W. H. Lee, P. D. Kessler, S. S. Gottlieb, N. Medina, and M. Yushak, "Prevention and reversal of nitrate tolerance in patients with congestive heart failure," The New England Journal of Medicine, vol. 317, no. 13, pp. 799-804, 1987.

[91] E. Noack and M. Feelisch, "Molecular mechanisms of nitrovasodilator bioactivation," Basic Research in Cardiology, vol. 86, supplement 2, pp. 37-50, 1991.

[92] C. Núñez, V. M. Víctor, R. Tur et al., "Discrepancies between nitroglycerin and NO-releasing drugs on mitochondrial oxygen consumption, vasoactivity, and the release of NO," Circulation Research, vol. 97, no. 10, pp. 1063-1069, 2005.

[93] M. Feelisch and M. Kelm, "Biotransformation of organic nitrates to nitric oxide by vascular smooth muscle and endothelial cells," Biochemical and Biophysical Research Communications, vol. 180, no. 1, pp. 286-293, 1991.

[94] K. Schror, S. Forster, and I. Woditsch, "On-line measurement of nitric oxide release from organic nitrates in the intact coronary circulation," Naunyn-Schmiedeberg's Archives of Pharmacology, vol. 344, no. 2, pp. 240-246, 1991.

[95] G. S. Marks, B. E. McLaughlin, K. Nakatsu, and J. F. Brien, "Direct evidence for nitric oxide formation from glyceryl trinitrate during incubation with intact bovine pulmonary artery," Canadian Journal of Physiology and Pharmacology, vol. 70, no. 2, pp. 308-311, 1992.

[96] S. J. Chung and H. L. Fung, "Relationship between nitroglycerin-induced vascular relaxation and nitric oxide production: probes with inhibitors and tolerance development," Biochemical Pharmacology, vol. 45, no. 1, pp. 157-163, 1993. 
[97] M. Feelisch, F. Brands, and M. Kelm, "Human endothelial cells bioactivate organic nitrates to nitric oxide. Implications for the reinforcement of endothelial defence mechanisms," European Journal of Clinical Investigation, vol. 25, no. 10, pp. 737-745, 1995.

[98] A. Mulsch, A. Bara, P. Mordvintcev, A. Vanin, and R. Busse, "Specificity of different organic nitrates to elicit NO formation in rabbit vascular tissues and organs in vivo," British Journal of Pharmacology, vol. 116, no. 6, pp. 2743-2749, 1995.

[99] W. N. Kuo, J. M. Kocis, M. J. Robinson, J. Nibbs, and R. Nayar, "Further study on s-nitrosation by nitrite," Frontiers in Bioscience, vol. 8, pp. a143-a147, 2003.

[100] D. J. Meyer, H. Kramer, and B. Ketterer, "Human glutathione transferase catalysis of the formation of S-nitrosoglutathione from organic nitrites plus glutathione," FEBS Letters, vol. 351, no. 3, pp. 427-428, 1994.

[101] H. Zeng, N. Y. Spencer, and N. Hogg, "Metabolism of S-nitrosoglutathione by endothelial cells," American Journal of Physiology, vol. 281, no. 1, pp. H432-H439, 2001.

[102] M. Sarr, I. Lobysheva, A. S. Diallo, J. C. Stoclet, V. B. SchiniKerth, and B. Muller, "Formation of releasable NO stores by S-nitrosoglutathione in arteries exhibiting tolerance to glyceryl-trinitrate," European Journal of Pharmacology, vol. 513, no. 1-2, pp. 119-123, 2005.

[103] M. W. Foster, T. J. McMahon, and J. S. Stamler, "S-nitrosylation in health and disease," Trends in Molecular Medicine, vol. 9, no. 4, pp. 160-168, 2003.

[104] P. R. A. Caramori, A. G. Adelman, E. R. Azevedo, G. E. Newton, A. B. Parker, and J. D. Parker, "Therapy with nitroglycerin increases coronary vasoconstriction in response to acetylcholine," Journal of the American College of Cardiology, vol. 32, no. 7, pp. 1969-1974, 1998.

[105] E. R. Azevedo, A. M. Schofield, S. Kelly, and J. D. Parker, "Nitroglycerin withdrawal increases endothelium-dependent vasomotor response to acetylcholine," Journal of the American College of Cardiology, vol. 37, no. 2, pp. 505-509, 2001.

[106] E. Schulz, N. Tsilimingas, R. Rinze et al., "Functional and biochemical analysis of endothelial (Dys)function and NO/ cGMP signaling in human blood vessels with and without nitroglycerin pretreatment," Circulation, vol. 105, no. 10, pp. 1170-1175, 2002.

[107] C. Napoli and L. J. Ignarro, "Nitric oxide and pathogenic mechanisms involved in the development of vascular diseases," Archives of Pharmacal Research, vol. 32, no. 8, pp. 1103-1108, 2009.

[108] G. Berkenboom, P. Unger, and J. Fontaine, "Atherosclerosis and responses of human isolated coronary arteries to endothelium-dependent and -independent vasodilators," Journal of Cardiovascular Pharmacology, vol. 14, supplement 11, pp. S35-S39, 1989.

[109] R. D. Fish, E. G. Nabel, A. P. Selwyn et al., "Responses of coronary arteries of cardiac transplant patients to acetylcholine," Journal of Clinical Investigation, vol. 81, no. 1, pp. 21-31, 1988.

[110] F. N. Ko, C. C. Wu, S. C. Kuo, F. Y. Lee, and C. M. Teng, "YC-1, a novel activator of platelet guanylate cyclase," Blood, vol. 84, no. 12 , pp. 4226-4233, 1994.

[111] C. C. Wu, F. N. Ko, S. C. Kuo, F. Y. Lee, and C. M. Teng, "YC-1 inhibited human platelet aggregation through NOindependent activation of soluble guanylate cyclase," British Journal of Pharmacology, vol. 116, no. 3, pp. 1973-1978, 1995.

[112] A. Friebe, G. Schultz, and D. Koesling, "Sensitizing soluble guanylyl cyclase to become a highly CO-sensitive enzyme," The EMBO Journal, vol. 15, no. 24, pp. 6863-6868, 1996.
[113] M. Feelisch, P. Kotsonis, J. Siebe, B. Clement, and H. H. H. W. Schmidt, "The soluble guanylyl cyclase inhibitor $1 \mathrm{H}$ $[1,2,4]$ oxadiazolo-[4,3,-a] quinoxalin-1-one is a nonselective heme protein inhibitor of nitric oxide synthase and other cytochrome P-450 enzymes involved in nitric oxide donor bioactivation," Molecular Pharmacology, vol. 56, no. 2, pp. 243-253, 1999.

[114] B. M. Bennett, B. J. McDonald, R. Nigam, and W. C. Simon, "Biotransformation of organic nitrates and vascular smooth muscle cell function," Trends in Pharmacological Sciences, vol. 15, no. 7, pp. 245-249, 1994.

[115] A. Mülsch, J. Bauersachs, A. Schäfer, J.-P. Stasch, R. Kast, and R. Busse, "Effect of YC-1, an NO-independent, superoxidesensitive stimulator of soluble guanylyl cyclase, on smooth muscle responsiveness to nitrovasodilators," British Journal of Pharmacology, vol. 120, no. 4, pp. 681-689, 1997.

[116] C. M. Teng, C. C. Wu, F. N. Ko, F. Y. Lee, and S. C. Kuo, "YC-1, a nitric oxide-independent activator of soluble guanylate cyclase, inhibits platelet-rich thrombosis in mice," European Journal of Pharmacology, vol. 320, no. 2-3, pp. 161-166, 1997.

[117] J. W. Wegener, I. Gath, U. Förstermann, and H. Nawrath, "Activation of soluble guanylyl cyclase by $\mathrm{YC}-1$ in aortic smooth muscle but not in ventricular myocardium from rat," British Journal of Pharmacology, vol. 122, no. 7, pp. 15231529, 1997.

[118] C.-C. Wu, F.-N. Ko, and C.-M. Teng, "Inhibition of platelet adhesion to collagen by cGMP-elevating agents," Biochemical and Biophysical Research Communications, vol. 231, no. 2, pp. 412-416, 1997.

[119] A. Straub, J. Benet-Buckholz, R. Fröde et al., "Metabolites of orally active NO-independent pyrazolopyridine stimulators of soluble guanylate cyclase," Bioorganic and Medicinal Chemistry, vol. 10, no. 6, pp. 1711-1717, 2002.

[120] J. P. Stasch, C. Alonso-Alija, H. Apeler et al., "Pharmacological actions of a novel NO-independent guanylyl cyclase stimulator, BAY 41-8543: in vitro studies," British Journal of Pharmacology, vol. 135, no. 2, pp. 333-343, 2002.

[121] J. P. Stasch, E. M. Becker, C. Alonso-Alija et al., "NO-independent regulatory site on soluble guanylate cyclase," Nature, vol. 410, no. 6825, pp. 212-215, 2001.

[122] O. V. Evgenov, D. S. Kohane, K. D. Bloch et al., "Inhaled agonists of soluble guanylate cyclase induce selective pulmonary vasodilation," American Journal of Respiratory and Critical Care Medicine, vol. 176, no. 11, pp. 1138-1145, 2007.

[123] C. F. Freitas, R. P. Morganti, J. M. Annichino-Bizzacchi, G. De Nucci, and E. Antunes, "Effect of bay 41-2272 in the pulmonary hypertension induced by heparin-protamine complex in anaesthetized dogs," Clinical and Experimental Pharmacology and Physiology, vol. 34, no. 1-2, pp. 10-14, 2007.

[124] P. Deruelle, T. R. Grover, L. Storme, and S. H. Abman, "Effects of BAY 41-2272, a soluble guanylate cyclase activator, on pulmonary vascular reactivity in the ovine fetus," American Journal of Physiology, vol. 288, no. 4, pp. L727-L733, 2005.

[125] P. Deruelle, T. R. Grover, and S. H. Abman, "Pulmonary vascular effects of nitric oxide-cGMP augmentation in a model of chronic pulmonary hypertension in fetal and neonatal sheep," American Journal of Physiology, vol. 289, no. 5, pp. L798-L806, 2005.

[126] P. Deruelle, V. Balasubramaniam, A. M. Kunig, G. J. Seedorf, N. E. Markham, and S. H. Abman, "BAY 41-2272, a direct activator of soluble guanylate cyclase, reduces right 
ventricular hypertrophy and prevents pulmonary vascular remodeling during chronic hypoxia in neonatal rats," Biology of the Neonate, vol. 90, no. 2, pp. 135-144, 2006.

[127] A. M. Badejo Jr., V. E. Nossaman, E. A. Pankey et al., "Pulmonary and systemic vasodilator responses to the soluble guanylyl cyclase stimulator, BAY 41-8543, are modulated by nitric oxide," American Journal of Physiology, vol. 299, no. 4, pp. H1153-H1159, 2010.

[128] O. V. Evgenov, F. Ichinose, N. V. Evgenov et al., "Soluble guanylate cyclase activator reverses acute pulmonary hypertension and augments the pulmonary vasodilator response to inhaled nitric oxide in awake lambs," Circulation, vol. 110, no. 15, pp. 2253-2259, 2004.

[129] S. A. Doggrell, "Clinical potential of nitric oxide-independent soluble guanylate cyclase activators," Current Opinion in Investigational Drugs, vol. 6, no. 9, pp. 874-878, 2005.

[130] P. Schmidt, M. Schramm, H. Schröder, and J.-P. Stasch, "Mechanisms of nitric oxide independent activation of soluble guanylyl cyclase," European Journal of Pharmacology, vol. 468, no. 3, pp. 167-174, 2003.

[131] J. P. Stasch, P. Schmidt, C. Alonso-Alija et al., "No- and haemindependent activation of soluble guanylyl cyclase: molecular basis and cardiovascular implications of a new pharmacological principle," British Journal of Pharmacology, vol. 136, no. 5, pp. 773-783, 2002.

[132] J. Mittendorf, S. Weigand, C. Alonso-Alija et al., "Discovery of riociguat (BAY 63-2521): a potent, oral stimulator of soluble guanylate cyclase for the treatment of pulmonary hypertension," ChemMedChem, vol. 4, no. 5, pp. 853-865, 2009.

[133] R. Frey, W. Mück, S. Unger, U. Artmeier-Brandt, G. Weimann, and G. Wensing, "Single-dose pharmacokinetics, pharmacodynamics, tolerability, and safety of the soluble guanylate cyclase stimulator BAY 63-2521: an ascending-dose study in healthy male volunteers," Journal of Clinical Pharmacology, vol. 48, no. 8, pp. 926-934, 2008.

[134] F. Grimminger, G. Weimann, R. Frey et al., "First acute haemodynamic study of soluble guanylate cyclase stimulator riociguat in pulmonary hypertension," European Respiratory Journal, vol. 33, no. 4, pp. 785-792, 2009.

[135] H. A. Ghofrani, M. M. Hoeper, M. Halank et al., "Riociguat for chronic thromboembolic pulmonary hypertension and pulmonary arterial hypertension: a phase II study," European Respiratory Journal, vol. 36, no. 4, pp. 792-799, 2010.

[136] M. S. Wolin, "Reactive oxygen species and the control of vascular function," American Journal of Physiology, vol. 296, no. 3, pp. H539-H549, 2009.

[137] P. M. Schmidt, M. Schramm, H. Schröder, F. Wunder, and J. P. Stasch, "Identification of residues crucially involved in the binding of the heme moiety of soluble guanylate cyclase," Journal of Biological Chemistry, vol. 279, no. 4, pp. 30253032, 2004.

[138] U. Schindler, H. Strobel, K. Schönafinger et al., "Biochemistry and pharmacology of novel anthranilic acid derivatives activating heme-oxidized soluble guanylyl cyclase," Molecular Pharmacology, vol. 69, no. 4, pp. 1260-1268, 2006.

[139] Y. Zhao, P. E. Brandish, M. DiValentin, J. P. M. Schelvis, G. T. Babcock, and M. A. Marletta, "Inhibition of soluble guanylate cyclase by ODQ," Biochemistry, vol. 39, no. 35, pp. 10848-10854, 2000.

[140] E. A. Dierks and J. N. Burstyn, "The deactivation of soluble guanylyl cyclase by redox-active agents," Archives of Biochemistry and Biophysics, vol. 351, no. 1, pp. 1-7, 1998.
[141] K. Schmidt, W. F. Graier, G. M. Kostner, B. Mayer, E. Bohme, and W. R. Kukovetz, "Oxidized low-density lipoprotein antagonizes the activation of purified soluble guanylate cyclase by endothelium-derived relaxing factor but does not interfere with its biosynthesis," Cellular Signalling, vol. 3, no. 4, pp. 361-367, 1991.

[142] J. Galle, A. Mulsch, R. Busse, and E. Bassenge, "Effects of native and oxidized low density lipoproteins on formation and inactivation of endothelium-derived relaxing factor," Arteriosclerosis and Thrombosis, vol. 11, no. 1, pp. 198-203, 1991.

[143] P. A. Craven and F. R. DeRubertis, "Restoration of the responsiveness of purified guanylate cyclase to nitrosoguanidine, nitric oxide, and related activators by heme and hemeproteins: evidence for involvement of the paramagnetic nitrosyl.heme complex in enzyme activation," Journal of Biological Chemistry, vol. 253, no. 23, pp. 8433-8443, 1978.

[144] F. R. DeRubertis, P. A. Craven, and D. W. Pratt, "Electron spin resonance study of the role of nitrosyl-heme in the activation of guanylate cyclase by nitrosoguanidine and related agonists," Biochemical and Biophysical Research Communications, vol. 83, no. 1, pp. 158-167, 1978.

[145] U. Elkayam, A. Roth, A. Mehra et al., "Randomized study to evaluate the relation between oral isosorbide dinitrate dosing interval and the development of early tolerance to its effect on left ventricular filling pressure in patients with chronic heart failure," Circulation, vol. 84, no. 5, pp. 2040-2048, 1991.

[146] U. Elkayam, "Tolerance to organic nitrates: evidence, mechanisms, clinical relevance, and strategies for prevention," Annals of Internal Medicine, vol. 114, no. 8, pp. 667-677, 1991.

[147] M. Schwemmer and E. Bassenge, "New approaches to overcome tolerance to nitrates," Cardiovascular Drugs and Therapy, vol. 17, no. 2, pp. 159-173, 2003.

[148] R. Dumitrascu, N. Weissmann, H. A. Ghofrani et al., "Activation of soluble guanylate cyclase reverses experimental pulmonary hypertension and vascular remodeling," Circulation, vol. 113, no. 2, pp. 286-295, 2006.

[149] J. P. Stasch, P. M. Schmidt, P. I. Nedvetsky et al., "Targeting the heme-oxidized nitric oxide receptor for selective vasodilatation of diseased blood vessels," Journal of Clinical Investigation, vol. 116, no. 9, pp. 2552-2561, 2006.

[150] G. Boerrigter, L. C. Costello-Boerrigter, A. Cataliotti, H. Lapp, J. P. Stasch, and J. C. Burnett Jr., "Targeting heme-oxidized soluble guanylate cyclase in experimental heart failure," Hypertension, vol. 49, no. 5, pp. 1128-1133, 2007.

[151] S. Thom, A. Hughes, G. Martin, and P. S. Sever, "Endothelium-dependent relaxation in isolated human arteries and veins," Clinical Science, vol. 73, no. 5, pp. 547-552, 1987.

[152] T. J. McMahon and P. J. Kadowitz, "Methylene blue inhibits neurogenic cholinergic vasodilator responses in the pulmonary vascular bed of the cat," American Journal of Physiology, vol. 263, no. 5, pp. L575-L584, 1992.

[153] D. B. Casey, A. M. Badejo Jr., J. S. Dhaliwal et al., "Analysis of responses to the Rho-kinase inhibitor Y-27632 in the pulmonary and systemic vascular bed of the rat," American Journal of Physiology, vol. 299, no. 1, pp. H184-H192, 2010.

[154] P. Vuorinen, I. Porsti, T. Metsa-Ketela, V. Manninen, H. Vapaatalo, and K. E. Laustiola, "Modification of nitrovasodilator effects on vascular smooth muscle by exogenous GTP and guanosine," Journal of Cardiovascular Pharmacology, vol. 18, no. 6, pp. 871-877, 1991. 
[155] C. J. Feng, D. Y. Cheng, A. D. Kaye, P. J. Kadowitz, and B. D. Nossaman, "Influence of N $(\omega)$-nitro-L-arginine methyl ester, LY83583, glybenclamide and L158809 on pulmonary circulation," European Journal of Pharmacology, vol. 263, no. 1-2, pp. 133-140, 1994.

[156] S. N. Murthy, B. D. Nossaman, and P. J. Kadowitz, "New approaches to the treatment of pulmonary hypertension: from bench to bedside," Cardiology in Review, vol. 18, no. 2, pp. 76-84, 2010.

[157] E. A. Pankey, M. Bhartiya, A. M. Badejo Jr. et al., "Pulmonary and systemic vasodilator responses to the soluble guanylyl cyclase activator, BAY 60-2770, are not dependent on endogenous nitric oxide or reduced heme," American Journal of Physiology, vol. 300, no. 3, pp. H792-H802, 2011.

[158] S. Korkmaz, T. Radovits, E. Barnucz et al., "Pharmacological activation of soluble guanylate cyclase protects the heart against ischemic injury," Circulation, vol. 120, no. 8, pp. 677686, 2009.

[159] T. Radovits, S. Korkmaz, C. Miesel-Gröschel et al., "Preconditioning with the soluble guanylate cyclase activator Cinaciguat reduces ischaemia-reperfusion injury after cardiopulmonary bypass," European Journal of Cardio-thoracic Surgery, vol. 39, no. 2, pp. 248-255, 2011.

[160] G. Boerrigter, H. Lapp, and J. C. Burnett Jr., "Modulation of cGMP in heart failure: a new therapeutic paradigm," Handbook of Experimental Pharmacology, vol. 191, pp. 485-506, 2009.

[161] B. D. Nossaman, H. A. Akuly, G. F. Lasker, V. E. Nossaman, P. A. Rothberg, and P. J. Kadowitz, "The reemergence of nitrite as a beneficial agent in the treatment of ischemic cardiovascular diseases," Asian Journal of Experimental Biological Sciences, vol. 1, no. 2, pp. 451-459, 2010.

[162] V. E. Nossaman, B. D. Nossaman, and P. J. Kadowitz, "Nitrates and nitrites in the treatment of ischemic cardiac disease," Cardiology in Review, vol. 18, no. 4, pp. 190-197, 2010.

[163] R. Frey, W. Mück, S. Unger, U. Artmeier-Brandt, G. Weimann, and G. Wensing, "Pharmacokinetics, pharmacodynamics, tolerability, and safety of the soluble guanylate cyclase activator cinaciguat (BAY 58-2667) in healthy male volunteers," Journal of Clinical Pharmacology, vol. 48, no. 12, pp. 1400-1410, 2008.

[164] H. Lapp, V. Mitrovic, N. Franz et al., "Cinaciguat (BAY 582667) improves cardiopulmonary hemodynamics in patients with acute decompensated heart failure," Circulation, vol. 119, no. 21, pp. 2781-2788, 2009. 


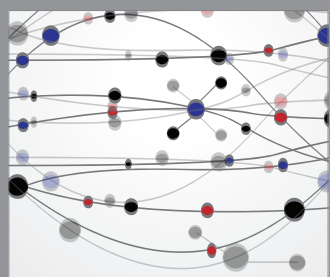

The Scientific World Journal
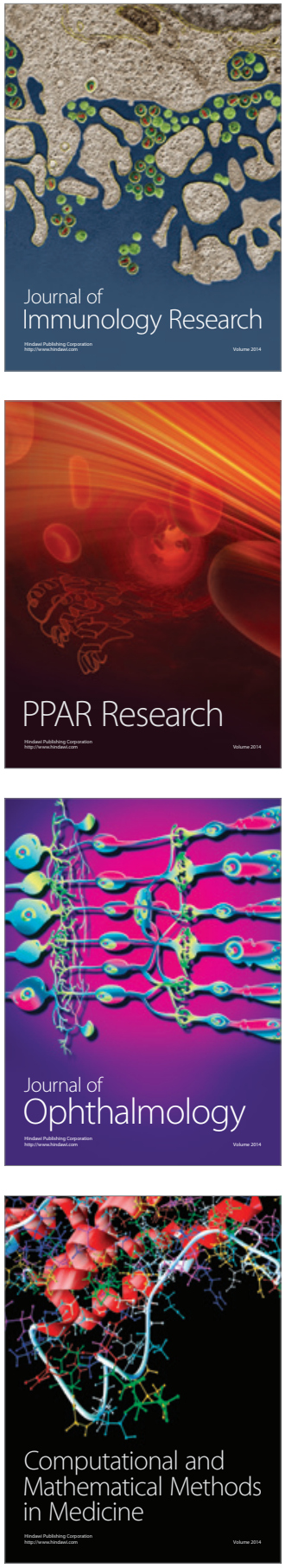

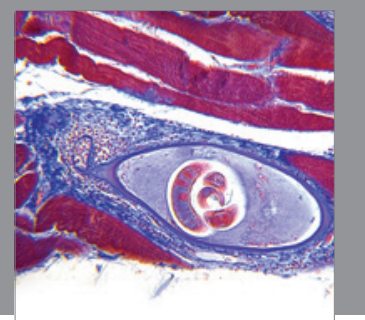

Gastroenterology

Research and Practice
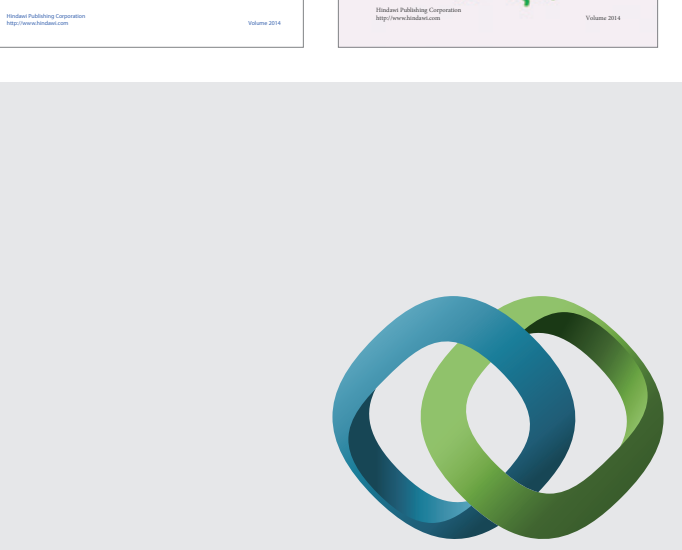

\section{Hindawi}

Submit your manuscripts at

http://www.hindawi.com
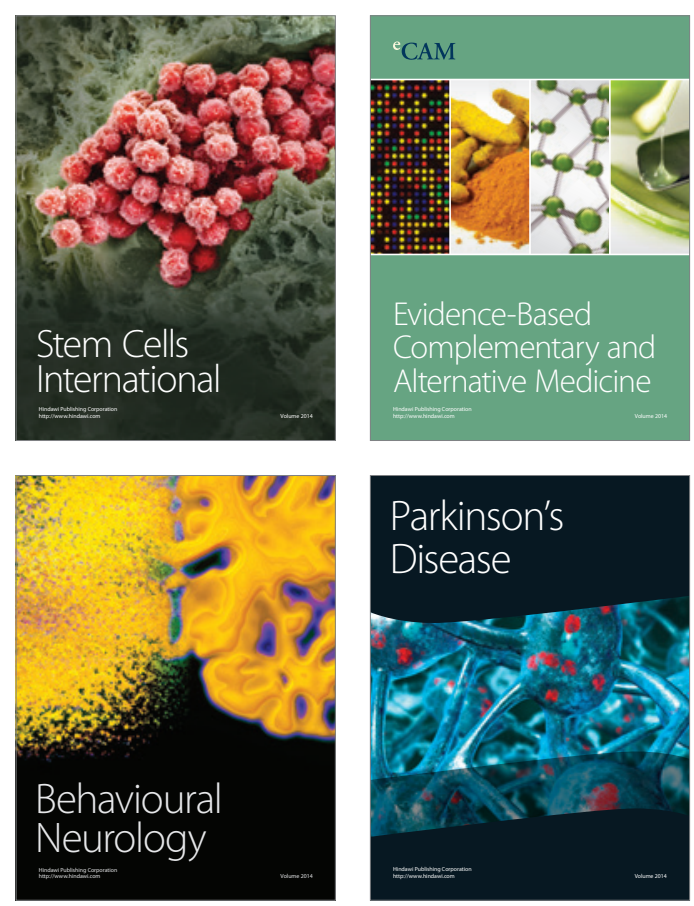

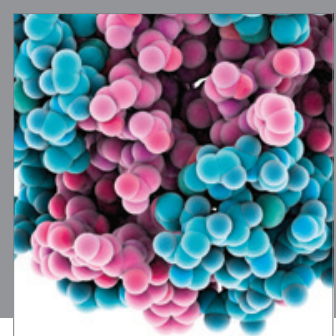

Journal of
Diabetes Research

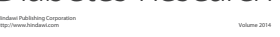

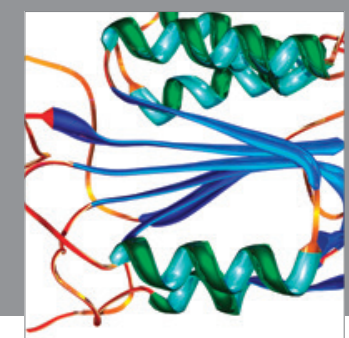

Disease Markers
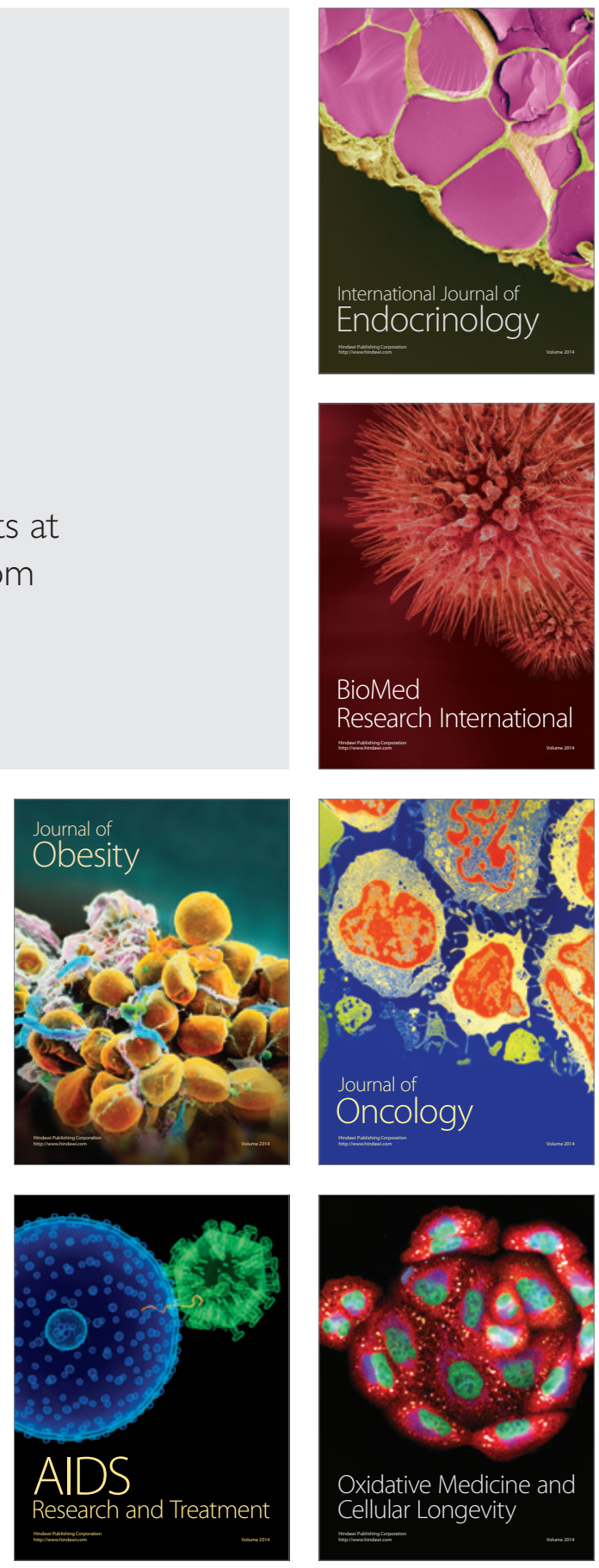